\title{
Nutritional status in patients with Idiopathic Pulmonary Fibrosis
}

\author{
Joaquim Gea*, Diana Badenes and Eva Balcells \\ Department of Respiratory Medicine, Hospital del Mar - IMIM. CEXS, Pompeu Fabra University. CIBERES, ISCiii. Barcelona
}

Idiopathic Pulmonary Fibrosis (FPI) is an interstitial pneumonia of unknown origin. Its respiratory symptoms are very limiting and its prognosis, despite the advent of new antifibrotic treatments (i.e. nintedanib, pyrfenidone), still remains poor [1,2]. The interest in IPF has increased in recent years due to both the appearance of these therapies and the important advances that have occurred in the knowledge of its pathophysiology and the imaging techniques. However, this interest has focused almost exclusively on the pulmonary involvement, characterized by mechanical changes derived from the rigidity of the lung parenchyma and the presence of areas with low ventilationperfusion ratios and a decrease in oxygen transfer through the alveolocapillar interphase [3]. Less known are the systemic manifestations of IPF. One of the most frequent is the presence of abnormalities in the nutritional status and/or body composition, which in turn can lead to muscle and bone problems. The prevalence of nutritional disorders has been estimated at $30 \%$ in hypoxemic IPF patients [4], almost doubling the percentage in those who are already candidates for lung transplantation [5]. The typical nutritional profile in patients with advanced FPI is a conserved body weight but with a decrease of more than $60 \%$ in lean mass [5], a circumstance generally associated with muscle dysfunction [6]. This disparity between body weight and lean mass can be explained by the frequent presence of a relatively high fat percentage in these patients [7]. Nevertheless, combined losses of body weight and lean mass can also be seen in some individuals [5]. It is worth noting that both body weight and lean mass loss are independent prognostic factors in IPF $[5,8]$, making an early and full evaluation of these circumstances essential in all patients. The latter implies that the assessment should not be limited to the calculation of the Ideal Body Weight percentage (\% IBW) or the Body Mass Index (BMI), but must be completed with blood analyses and determination of body composition, especially of the fat-free mass index (FFMI, usually obtained through bioelectric impedance). An important consequence of lean mass loss is muscle dysfunction. In fact, the weak relationship between pulmonary function and exercise capacity observed in many IPF patients already suggests the presence of this, and other additional factors. In spite of that, only a few studies have devoted their attention to muscle function in IPF patients. These studies have clearly demonstrated that there is muscle weakness both in respiratory and peripheral muscles [9-11], which undoubtedly contributes to the reduction in physical activity and worse quality of life shown by the patients $[9,12]$.

However, as already demonstrated in other chronic respiratory diseases, the cause of the nutritional abnormalities and muscle dysfunction observed in IPF is probably multifactorial. On the one hand, there is a reduction in the level of physical activity that initially results from pulmonary involvement and its psychological consequences (basically anxiety and depression), but subsequently leads to deconditioning of different body components, such as the cardiovascular system, limb muscles and bones, further limiting physical capacity. On the other hand, IPF patients can have difficulties in feeding as a result of severe dyspnea. However, there are other possible etiological factors, such as pulmonary and systemic oxidative stress and inflammation $[13,14]$ and hypoxia, all of them are able to induce protein content loss, due to both decreased synthesis and increased catabolism $[15,16]$. It is interesting to note here that the "spill over" theory (systemic extension of inflammation from a predominantly pulmonary location to other organs through the blood stream) has also been invoked in IPF and would be especially important during exacerbations [17]. Hypoxia also hinders the action of certain hormones and active peptides, such as leptin and ghreline (an endogenous secretagogue of the growth hormone) [6]. Furthermore, aging and the most frequent comorbidities of IPF can also favor nutritional abnormalities. This is the case of diabetes mellitus type II, present in up to $35 \%$ of patients with IPF, even after the exclusion of those who have received systemic corticosteroids for a long time $[18,19]$. It is also well known that some patients with COPD (an entity in which nutritional disturbances are also frequent) associate areas of fibrosis [20], and vice versa up to one third of IPF patients also exhibit pulmonary emphysema [21,22]. Vitamin D deficiency, with a prevalence of $20-40 \%$ in these patients $[23,24]$, can also contribute to muscle and bone mass loss, and also seems to contribute to the negative prognosis of the pulmonary disease [25]. This vitamin deficit is probably being the result of both an inappropriate diet and the restriction in daily outdoor activities due to the primarily respiratory limitation [26]. Moreover, since IPF usually appears after the age of 50 , the loss of muscle mass and function characteristic of elderly patients (sarcopenia) can be added to previous factors [27]. Finally, we should mention the deleterious effects of some treatments commonly used in IPF, such as systemic corticosteroids, which can produce nutritional alterations through a reduction in protein synthesis and an increase in their degradation [28,29], as well as induce acute and chronic myopathies, both characterized by muscle weakness $[29,30]$. On their own both nintedanib and pirfenidone could facilitate body weight and lean mass wasting due to their anorexic and gastrointestinal side effects [31]. However, pirfenidone could also have a positive effect on the nutritional status, since it inhibits transforming growth factor beta (TFG- $\beta$ ) [31], which has been implicated in weight loss in various disorders [32].

Correspondence to: J Gea, Pneumology Service, Hospital del Mar, Pg Marítim 27, 08003 Barcelona, Spain, E-mail: quim.gea@upf.edu

Received: March 23, 2018; Accepted: March 27, 2018; Published: March 29, 2018 
Surprisingly, and despite all these evidences, the clinical guidelines for IPF management do not give specific recommendations for nutritional abnormalities associated with this disorder [33,34]. However, it appears reasonable to propose general measures related to lifestyle, such as appropriate diet and level of physical activity. It is interesting to note that there are some reports showing the effects of some diet schedules even in the occurrence and prognosis of IPF. Miyake et al. in particular, have shown the effects of a diet rich in fruit for the prevention of this lung disease [35], while the intake of saturated fatty acids seems to have the opposite effect, increasing the risk of suffering IPF [36]. The use of nutritional supplements can be useful when diet recommendations become insufficient. It is also recommendable to try to achieve a good control of the lung disease [6], controlling hypoxemia and avoiding exacerbations due to the effect they have on systemic inflammation and physical activity, as well as refraining from an improper use of systemic corticosteroids. Rehabilitation programs in turn, and especially those that include general and muscle training, have proven to be beneficial at least for muscle function [10,37] although their results can be further improved ensuring first a good nutritional substrate. Finally, even though anabolic drugs (eg, androgenic derivates or growth hormone secretagogues) have demonstrated no benefits in IPF patients in particular, it seems reasonable to use them in cases of severe malnutrition.

As a summary, abnormal nutritional status and/or body composition are frequent in IPF patients, and since they influence prognosis, clinicians must be alert for an early detection. Once the problem has been identified, healthy habits, including an appropriate diet and a good level of physical activity, should be recommended. The use of nutritional supplements may also be necessary in some cases. Moreover, the lung disease should be well controlled, improving oxygenation, avoiding exacerbations and harmful treatments, and initiating training with programs adapted to the patient's possibilities. Although their effects are controversial, anabolic drugs may be recommended in the most serious nutritional depletions.

\section{Acknowledgements}

To Jonathan McFarland for his editing help. Union)

Partially funded by SAF2014-54371 (FEDER Program, European

\section{References}

1. Richeldi L, Collard HR, Jones MG (2017) Idiopathic pulmonary fibrosis. Lancet 389: 1941-1952. [Crossref]

2. Sgalla G, Iovene B, Calvello M, Ori M, Varone F, et al. (2018) Idiopathic pulmonary fibrosis: pathogenesis and management. Respir Res 19: 32. [Crossref]

3. Agustí AG, Roca J, Gea J, Wagner PD, Xaubet A, et al. (1991) Mechanisms of gasexchange impairment in idiopathic pulmonary fibrosis. Am Rev Respir Dis 143: 219225. [Crossref]

4. Chailleux E, Fauroux B, Binet F, Dautzenberg B, Polu JM (1996) Predictors of survival in patients receiving domiciliary oxygen therapy or mechanical ventilation. A 10-year analysis of ANTADIR Observatory. Chest 109: 741-749. [Crossref]

5. Schwebel C, Pin I, Barnoud D, Devouassoux G, Brichon PY, et al. (2000) Prevelence and consequences of nutritional depletion in lung transplant candidates. Eur Respir $J$ 16: 1050-1055. [Crossref]

6. Gea J, Sancho-Muñoz A, Chalela R (2018) Nutritional status and muscle dysfunction in chronic respiratory diseases: stable phase versus acute exacerbations. J Thorac Dis In press.

7. Madill J, Maurer JR, de Hoyos A (1993) A comparison of preoperative and postoperative nutritional states of lung transplant recipients. Transplantation 56: 347-350. [Crossref]

8. Alakhras M, Decker PA, Nadrous HF, Collazo-Clavell M, Ryu JH (2007) Body mass index and mortality in patients with idiopathic pulmonary fibrosis. Chest 131: 14481453. [Crossref]
9. Kozu R, Jenkins S, Senjyu H (2014) Evaluation of activity limitation in patients with idiopathic pulmonary fibrosis grouped according to Medical Research Council dyspnea grade. Arch Phys Med Rehabil 95: 950-955. [Crossref]

10. Jackson RM, Gómez-Marín OW, Ramos CF, Sol CM, Cohen MI, et al. (2014) Exercise limitation in IPF patients: a randomized trial of pulmonary rehabilitation. Lung 192 367-376. [Crossref]

11. Nishiyama O1, Taniguchi H, Kondoh Y, Kimura T, Ogawa T, et al. (2005) Quadriceps weakness is related to exercise capacity in idiopathic pulmonary fibrosis. Chest 127 : 2028-2033. [Crossref]

12. van Manen MJ, Geelhoed JJ, Tak NC, Wijsenbeek MS (2017) Optimizing quality of life in patients with idiopathic pulmonary fibrosis. Ther Adv Respir Dis 11: 157-169. [Crossref]

13. Malli F, Bardaka F, Tsilioni I, Karetsi E, Gourgoulianis KI, et al. (2013) 8-isoprostane levels in serum and bronchoalveolar lavage in idiopathic pulmonary fibrosis and sarcoidosis. Food Chem Toxicol 61: 160-163. [Crossref]

14. Meltzer EB, Noble PW (2008) Idiopathic pulmonary fibrosis. Orphanet J Rare Dis 3 : 8. [Crossref]

15. Argiles JM, Busquets S, Stemmler B, Lopez-Soriano FJ (2015) Cachexia and sarcopenia: mechanisms and potential targets for intervention. Curr Opin Pharmacol 22: 100-106. [Crossref]

16. Bunn HF, Poyton RO (1996) Oxygen sensing and molecular adaptation to hypoxia Physiol Rev 76: 839-885. [Crossref]

17. Collard HR, Calfee CS, Wolters PJ, Song JW, Hong SB, et al. (2010) Plasma biomarker profiles in acute exacerbation of idiopathic pulmonary fibrosis. Am J Physiol Lung Cell Mol Physiol 299: L3-L7. [Crossref]

18. Enomoto T, Usuki J, Azuma A, Nakagawa T, Kudoh S (2003) Diabetes mellitus may increase risk for idiopathic pulmonary fibrosis. Chest 123: 2007-2011. [Crossref]

19. Gribbin J, Hubbard R, Smith C (2009) Role of diabetes mellitus and gastro-oesophagea reflux in the aetiology of idiopathic pulmonary fibrosis. Respir Med 103: 927-931. [Crossref]

20. Vogelmeier CF, Criner GJ, Martínez FJ, Anzueto A, Barnes PJ, et al. (2017) Global Strategy for the Diagnosis, Management, and Prevention of Chronic Obstructive Lung Disease 2017 Report: GOLD Executive Summary. Arch Bronconeumol 53: 128-149. [Crossref]

21. Kurashima K, Takayanagi N, Tsuchiya N, Kanauchi T, Ueda M, et al. (2010) The effect of emphysema on lung function and survival in patients with idiopathic pulmonary fibrosis. Respirology 15: 843-848. [Crossref]

22. Ryerson CJ, Hartman T, Elicker BM, Ley B, Lee JS, et al. (2013) Clinical features and outcomes in combined pulmonary fibrosis and emphysema in idiopathic pulmonary fibrosis. Chest 144: 234-240. [Crossref]

23. Hagaman JT, Panos RJ, McCormack FX, Thakar CV, Wikenheiser-Brokamp KA, et al (2011) Vitamin D deficiency and reduced lung function in connective tissue-associated interstitial lung diseases. Chest 139: 353-360. [Crossref]

24. Elnady HG, el-Alameey IR, Kamel TB, El feky R, Youness ER, Kholoussi S. Predictors of reduced serum vitamin D levels among Egyptian children with interstitial lung disease. J Arab Soc Med Res 2014:67-74.

25. Zhang Z, Yu X, Fang X, Liang A, Yu Z, et al. (2015) Preventive effects of vitamin $\mathrm{D}$ treatment on bleomycin-induced pulmonary fibrosis. Sci Rep 5: 17638. [Crossref]

26. Bahmer T, Kirsten AM, Waschki B, Rabe KF, Magnussen H, et al. (2017) Prognosis and longitudinal changes of physical activity in idiopathic pulmonary fibrosis. BMC Pulm Med 17: 104. [Crossref]

27. Argiles JM1, Busquets S, Felipe A, López-Soriano FJ (2006) Muscle wasting in cancer and ageing: cachexia versus sarcopenia. Adv Gerontol 18: 39-54. [Crossref]

28. Hasselgren PO, Alamdari N, Aversa Z, Gonnella P, Smith IJ, et al. (2010) Corticosteroids and muscle wasting: role of transcription factors, nuclear cofactors, and hyperacetylation. Curr Opin Clin Nutr Metab Care; 13:423-8. [Crossref]

29. Schakman O, Gilson H, Kalista S, Thissen JP (2009) Mechanisms of muscle atrophy induced by glucocorticoids. Horm Res 72 Suppl 1: 36-41. [Crossref]

30. Goldberg AL, Goodman HM (1969) Relationship between cortisone and muscle work in determining muscle size. $J$ Physiol 200: 667-675. [Crossref]

31. Rogliani P, Calzetta L, Cavalli F, Matera MG, Cazzola M (2016) Pirfenidone, nintedanib and $\mathrm{N}$-acetylcysteine for the treatment of idiopathic pulmonary fibrosis: A systematic review and meta-analysis. Pulm Pharmacol Ther 40: 95-103. [Crossref] 
32. Chen JL, Walton KL, Hagg A, Colgan TD, Johnson K, et al. (2017) Specific targeting of TGF- $\beta$ family ligands demonstrates distinct roles in the regulation of muscle mass in health and disease. Proc Natl Acad Sci USA 114: E5266-75. [Crossref]

33. Raghu G, Collard HR, Egan JJ, Martinez FJ, Behr J, et al. (2011) An official ATS/ ERS/JRS/ALAT statement: idiopathic pulmonary fibrosis: evidence-based guidelines for diagnosis and management. Am J Respir Crit Care Med 183:788-824. [Crossref]

34. Xaubet A, Molina-Molina M, Acosta O, Bollo E, Castillo D, et al. (2017) Guidelines for the medical treatment of idiopathic pulmonary fibrosis. Arch Bronconeumol 53: 263-269. [Crossref]
35. Miyake Y, Sasaki S, Yokoyama T, Chida K, Azuma A, et al. (2004) Vegetable, fruit, and cereal intake and risk of idiopathic pulmonary fibrosis in Japan. Ann Nutr Metab 48: 390-397. [Crossref]

36. Miyake Y, Sasaki S, Yokoyama T, Chida K, Azuma A, et al. (2006) Dietary fat and meat intake and idiopathic pulmonary fibrosis: a case-control study in Japan. Int J Tuberc Lung Dis 10: 333-339. [Crossref]

37. Kozu R, Senjyu H, Jenkins SC, Mukae H, Sakamoto N, et al. (2011) Differences in response to pulmonary rehabilitation in idiopathic pulmonary fibrosis and chronic obstructive pulmonary disease. Respiration 81: 196-205. [Crossref]

Copyright: $@ 2018$ Gea J. This is an open-access article distributed under the terms of the Creative Commons Attribution License, which permits unrestricted use, distribution, and reproduction in any medium, provided the original author and source are credited. 